\title{
ALGUMAS POSSIBILIDADES PARA PENSAR AS ATITUDES VIOLENTAS CONTRA PESSOAS LGBT
}

\author{
SOME POSSIBILITIES TO UNDERSTAND VIOLENT ATTITUDES AGAINST \\ LGBT PEOPLE
}

Matheus Mendes Pascoal ${ }^{1}$

RESUMO: A peça de teatro Campeonato Interdrag de Gaymada apresentada no Festival de Teatro de Curitiba 2017 trouxe a questão da agressividade contra o público trans e LGBT. Parodiando o jogo chamado de "Queimada" ou "Caçador", onde os adversários (pessoas do outro time) são "caçados" e "queimados". A intolerância e o ódio se fazendo ato remetem ao que Freud (I895) chamou de processo primário, onde a energia psíquica escoa livremente, passando sem barreira de representação. Existe na sociedade um padrão de exclusão das pessoas com opções sexuais divergentes do que é socialmente, culturalmente e historicamente aceito ou acordado. A perversidade do sujeito homofóbico pode ser entendida como uma válvula de escape para o sentimento de culpa que carrega em relação a experiências inconscientes frente ao objeto amado, onde, na impossibilidade do recalque, se abrem vias para um sentimento de culpa, podendo levar o sujeito a práticas homofóbicas

num circuito

perverso e compensatório para o mal-estar experienciado. O objetivo desse artigo é discutir, sob o olhar da psicanálise, o que leva algumas pessoas a terem atitudes agressivas, violentas ou persecutórias, que visam "queimar" seus semelhantes. Através da psicanálise, acreditamos que existam outros caminhos de lidar com o ódio, uma deles é torná-lo em palavra.

Palavras-chave: homofobia. Preconceito. Agressividade. população transexual.

ABSTRACT: A play entitled Campeonato Interdrag de Gaymada, presented at the 2017 Curitiba Theater Festival, brought to the light issues such as the aggression against Trans and LGBT population by the performance of a game called "Queimada" or "Caçador", which means to burn or to hunt the opponents (players from another team). Intolerance and hate becoming act, a primary process, according to Freud (1895), in which psychic energy flows freely without representation. There is in society an exclusion pattern of people with different sexual options, since they diverge from what is socially, culturally and historically accepted or agreed. The perversity of a homophobic individual may be understood as an outlet to guilty

\footnotetext{
I Graduando em Enfermagem-Centro Universitário Integrado, Editor Júnior da SaBios, Membro da LAESM e LADCIST.E-mail:matheus_mendesis@hotmail.com
} 
related to unconscious experiences towards a loved object when faced to inability to deal to repression, which may induce the person to homophobia, in a perverse and compensatory circuit to the experienced discomfort. The aim of this text is to discuss, in a psychoanalytic view, what makes some people act aggressively, violently or in a persecutory mode, aiming to "burn" their counterparts. By means of psychoanalysis it is possible to believe that there are alternative ways to deal with hate, such as talking about it.

key-words: Homophobia. Prejudice. Aggression. transsexual population.

\section{INTRODUÇÃO}

A partir de uma peça de teatro "Campeonato Interdrag de Gaymada - ocupa espaço público com diversão e diversidade sexual", apresentada no Festival de Teatro de Curitiba 2017, parodia um jogo infanto-juvenil chamado Queimada, Caçador, Matamata, entre outros nomes, e é protagonizado por dragqueens, que iniciam a performance com danças até que um número satisfatório de espectadores tenha se reunido ao redor dos atores. Os atores então desfilam com as bandeiras do feminismo, trans e LGBT e entoam hino criado pela própria companhia de teatro. $\mathrm{O}$ espetáculo tem I hora de duração, com danças, performances, desfile com bandeiras, e a partida de queimada. Em uma fala inicial do espetáculo, os atores explicam que os objetivos da peça são propiciar o surgimento e a observação de novos talentos da população lésbica, trans, bissexual e gay, e de reflexão.

Durante o jogo de Gaymada, as pessoas eram convidadas a participar da atividade. Ao final do dia, já com um numero reduzido de público, os artistas se reuniram com algumas pessoas que assistiram à peça para uma discussão sobre as percepções das manifestações e como os participantes se sentiram na condição de "caçadores" e de "queimados", visando o fomento do pensamento crítico sobre a questão da agressividade, da aceitação dos diferentes, da exclusão, entre outros temas que surgissem, tais como preconceito, violência, homo/trans/lesbio/bifobia e a representação LGBT no espaço público com o intuito de demonstrar a realidade do público LGBT através do jogo gaymada, onde os sujeitos estão sujeitos a receber boladas pelas costas e "morrer", sendo excluídos do jogo, similarmente ao que ocorre nos palcos da sociedade. A atração artística embasa-se nos princípios elementares dos 
direitos humanos, que garantem o direito de expressão de todas as manifestações de performatividade de gênero. Mais do que isso, o jogo escolhido traz à luz características peculiares, onde os "oponentes", "inimigos", ou simplesmente "pessoas do outro time" são atingidas por bolada, geralmente pelas costas, uma vez que as pessoas tentam se proteger do impacto e correm, tentando fugir, e após haverem sido atingidas, ou "queimadas", são excluídas do jogo. Metáfora que exemplifica condição que muitos passam no "jogo da vida".

Queimada, cemitério, mata-mata, queimado, caçador ou baleado é um jogo cuja essência consiste em acertar a bola, por meio de arremessos, nos jogadores do time adversário até que todos os jogadores "queimados" se desloquem para o campo de queimados (OLIVEIRA; LUZ, 2016).

É a partir do "queimar”, do jogador ser atingido e excluído do jogo, que surge a reflexão de que o que acontece no jogo se passa na sociedade, ou seja, expressões violentas direcionadas a pessoas LGBT'S, sendo comum nessas manifestações a intolerância e o ódio se fazendo ato, remetendo-se ao que Freud (I895) chamou de processo primário, onde a energia psíquica escoa livremente, passando sem barreira de representação, de forma imediata.

Sendo a partir das colocações acima que demarcam que a violência contra pessoas lgbt's que vem aumentando significativamente em nosso país. Que tais pessoas, além de não se enquadrarem no padrão social heteronormativo, ainda sofrem com atitudes machistas e violentas. A intolerância e a falta de diálogo aliadas à ignorância em relação ao tema contribuem para esse contexto. Diante de tais fatos, notou-se a necessidade de estudar tamanho absurdo e desrespeito para com o indivíduo e fomentar o entendimento, respeito, e aceitação daqueles com opções diferentes de vida.

Então, este artigo consiste em um estudo bibliográfico a partir da análise da peça, com proposta de discutir temas relativos à coletividade tais como aceitação, preconceito, agressividade, entre outros. O objetivo é discutir, sob o olhar da psicanalise, o que leva algumas pessoas a terem atitudes agressivas, violentas ou persecutórias, que visam "queimar" seus semelhantes. 


\section{DESENVOLVIMENTO}

Segundo Espindola (2015) lgbtfobia demostra atitudes de violência (física, psicológica) direcionada a aqueles que manifestam sua sexualidade diferente dos padrões que a sociedade tem como modelo. Onde o sujeito lgbtfobico, encontra um modo de inferiorizar aquele diferente, seja com suas palavras de ódio ou com atos violentos que podem levar a morte da vitima.

O termo indica o ódio e a aversão aos homossexuais e a todas as outras
manifestações da sexualidade não hegemônica ou de expressões de gênero
distintas dos padrões normativos do masculino e do feminino. A
LGBTfobia é, segundo Daniel Borrillo, do mesmo modo que a xenofobia,
o racismo ou o antissemitismo, uma manifestação arbitrária que consiste
em qualificar o outro como o contrário, inferior ou anormal, referindo-se a
um prejulgamento que consiste em acreditar na supremacia da
heterossexualidade. (ESPINDOLA, 20I5, P.ı)

Mais propriamente sobre o ato de agressividade contra LGBTs, Oliveira (2014) descreve o ato agressivo como uma atitude preconceituosa, que reflete um gozo, o ódio de parte da sociedade em direção a um grupo de pessoas, que são massacradas moralmente e marginalizadas, obrigadas a aguentarem as mais cruéis práticas de violências (práticas Lgbtfóbicas físicas, políticas e psicológicas), portanto, demostrando o gozo perverso. O autor descreve como violência politica lgbtfóbica, pontuando o projeto de cura gay, proposto por deputados que expressavam, de maneira violenta, a homossexualidade como algo curável.

A homofobia se caracteriza, portanto, como um sintoma múltiplo, manifestado socialmente, mas que advém das representações do conteúdo inconsciente que é peculiar dos processos constitutivos da subjetividade do sujeito (OLIVEIRA, 2014, P.136).

Oliveira (2014) pontua que por mais que a homofobia seja um conteúdo encontrado em vários cenários da sociedade, ela não pode ser definida por uma causa específica, a homofobia seria um traço singular de alguns sujeitos.

Pensando em algumas possibilidades que levam um sujeito a ter atitudes lgbt fobias, pode-se exemplificar um deles na canção de Caetano Veloso, em que "Narciso acha feio o que não é espelho", e que contribui com o que Freud (1913) nomeou de formação reativa, ou seja, algo que impulsiona o sujeito ao oposto do seu desejo. Nas palavras de Freud, "na vida mental forças motivadoras que ocasionam a 
substituição pelo oposto, na forma do que é conhecido como formação reativa" (I913, p.24). Logo, aquilo que se é e não se quer admitir deve ser destruído no outro.

Oliveira (2014) auxilia a pensar a perversidade do sujeito homofóbico em seus atos como uma válvula frente ao sentimento de culpa que carrega em relação a experiências inconscientes frente ao objeto amado. $\mathrm{Na}$ impossibilidade do recalque, se abrem as vias para um sentimento de culpa, podendo levar o sujeito a práticas lgbt fóbicas num circuito perverso e compensatório para o mal-estar experienciado.

Outra explicação para tal preconceito é porque os LGBTs podem estar na indulgência de um "tabu" quando se desviam da "norma", das convenções sociais, religiosas e culturais. Os outros se ressentem, pois todos deveriam "seguir as regras". E não somente o que é tabu é considerado errado, ou impuro, mas quem o pratica torna-se também em tabu (FREUD, 1913/14).

Sabe-se que o ser humano abdica de muitos dos seus prazeres instituais e sexuais em troca da segurança de viver em sociedade. Submete-se a normas e padrões de comportamento e ressente-se quando outros seres humanos assumem e dão vazão aos seus sentimentos, instintos, pulsões, e permitem-se confrontar tais normas em busca do seu prazer, assumindo publicamente seus desejos e sexualidade. Em O Mal Estar na Civilização (1930/2011), Freud comenta sobre o "narcisismo das pequenas diferenças", em que se considerada inferior o outro, o diferente, o estranho. Daí pode se explicar o preconceito e a agressividade para com os transexuais, pois "sempre é possível ligar um grande número de pessoas pelo amor, desde que restem outras para que se exteriorize a agressividade" (FREUD, 1930/20II, p. 6o).

A escolha do objeto do indivíduo, de acordo com Freud (1930/201I, p. 50) é geralmente reduzida ao sexo oposto, e o que disso difere é tratado como perversão. A premissa de uma vida sexual uniforme para todos não respeita as desigualdades na constituição inata e adquirida dos seres humanos e se torna, portanto, "fonte de grave injustiça".

Freud (1919) em O estranho, afirma que coisas, pessoas, impressões, eventos e situações conseguem despertar em nós um sentimento de estranheza de forma particularmente poderosa e definida, pois esse estranho não é nada novo ou alheio, porém algo que é familiar e há muito estabelecido na mente, e que somente se 
alienou desta através do processo da repressão. O estranho provém de algo familiar que foi reprimido. Com isso podemos pensar que é algo que há dentro de todos, mas o modo que vamos lidar com o que se apresenta como familiar em nós é singular. É nesses casos singulares que se manifestam casos de lgbt fobia.

O que é familiar é considerado confortável, pertencente, domesticado, “despertando uma sensação de repouso agradável e de segurança”. O outro, diferente, “o estranho" a mim, me é desconfortável, me causa mal-estar, repulsa, horror. Todavia, o que é estranho não necessariamente me é "não-familiar", pelo contrário, "o estranho é aquela categoria do assustador que remete ao que é conhecido, de velho, e há muito familiar” (FREUD, I919, p. 140). A partir destas construções de Freud (1919), é possível pensar sobre o tema, onde o que se nomeia como estranho poderia ser entendido como o que há de diferente, que causa um sentimento de horror, essa sensação que se apresenta como estranha e inconscientemente familiar ao sujeito lgbt fóbico, remete a algo de si.

Infelizmente "a civilização espera prevenir os excessos mais grosseiros da violência conferindo a si mesma o direito de praticar a violência contra os infratores". Entende-se a agressividade como algo inato ao ser humano, e esta pode se apresentar através do fenômeno da violência na sociedade por aqueles que acham que podem bater e matar em nome daquilo que acham certo. Freud descreveu situações que são atuais no mundo, e onde em alguns países pessoas LGBT pagam com sua liberdade ou com a própria vida, apanhando de autoridades locais e de pessoas comuns (FREUD, 1930/201I, p. 58).

\section{CONCLUSÃO}

Freud (1920) descreve sobre um caso de uma homossexual, que em partes sofre preconceito familiar e social. Mas cabe a nos, futuros psicólogos, seguirmos as orientações que Freud (1920) postula, pois o mesmo alerta que ao amarmos, podemos estar amando um objeto que carregue em si um ideal de homem e mulher. Seriamos todos homo/bissexuais? Freud naquele momento descreve que sim, reforçando a ideia de que a natureza da sexualidade humana é bissexual, e que a homossexualidade não deve ser vista como objeto de pesquisa, afim de compreensão patológica. 
Descrevemos isso, para que fique claro, que não foi objetivo da pesquisa se deter a entender a gênese da homossexualidade, mas sim, um esforço foi feito para a compreensão de possibilidades de entendimento de atitudes lgbt fóbicas através da psicanálise.

A maioria das questões enfocadas nesse trabalho nos permitiu entender atitudes lgbt fóbicas como algo inconsciente no sujeito agressor. De modo geral, nesses casos, Oliveira (2014) pontua que a educação e suas práticas pedagógicas como possibilidade de reconduzir a violência de sujeitos homofóbicos, entendendo que somos, também, constituídos no meio educacional, e que isso, de algum modo, nos faz entender sobre o mundo e a educação, e pode auxiliar (desde a primeira infância) o sujeito a entender a sua sexualidade e respeitar o outro como diferente.

Seja qual for o modo de analisarmos a homofobia, algo que entendemos como possibilidade de reversão do quadro é o sujeito poder falar disso. É comum ver que nas manifestações homofóbicas a intolerância e o ódio se fazendo ato, fazendo-nos pensar sobre o que Freud (I895) chamou de processo primário, onde a energia psíquica escoa de maneira livre, passando sem a barreira de uma representação, de forma imediata, como se não houvesse representante para sustentar isso que é aversivo no outro e/ou em si. Ainda, pensando através da psicanálise, acreditamos que existam outros caminhos de lidar com o ódio, um deles é torná-lo em palavras.

\section{REFERÊNCIAS}

ESPINDOLA, B. C., Cidadania Na Sociedade Em Rede: O Ciberativismo E O Combate À Lgbtfobia. $3^{\circ}$ Congresso Internacional de Direito e Contemporaneidade. UFSM, Santa Maria -RS. 2015.

FREUD, S. (1895). Projeto para uma psicologia científica. In: FREUD, S. Obras completas. Rio de Janeiro: Imago, i996. vol. I.

• (1919) O "Estranho" In FREUD, S. Uma neurose infantil e outros trabalhos

(1917-1918); tradução sob a direção de Jayme Salomão. Rio de Janeiro: Imago, I996. 
(Edição Standard Brasileira das Obras Psicológicas Completas de Sigmund Freud, v. 17).

. (1930) “O Mal-Estar Na Civilização” In FREUD, S.; tradução Paulo César de Souza - São Paulo: Penguin Classics Companhia de Letras, 201 .

. (1920) “A Psicogênese De Um Caso De Homossexualismo Numa Mulher” In FREUD, S.; tradução Paulo César de Souza - São Paulo: Penguin Classics Companhia de Letras, 20II.

(1913) “O Tema Dos Três Escrínios” In FREUD, S.; tradução Paulo César de Souza - São Paulo: Penguin Classics Companhia de Letras, 201 .

ONU. Disponível em: https://nacoesunidas.org/onu-lembra-dia-internacionalcontra-a-homofobia-e-a-transfobia-veja-principais-abrasil/ \&ei=roCnDPqM\&lc=pt-

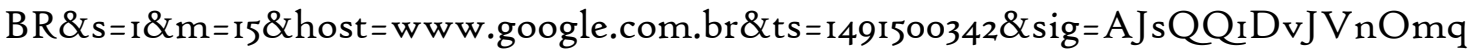
ko2CWoyAkwjaDo-BUtmw Acesso em 31/o3/2017

OLIVEIRA, V.J.M.; LUIZ, I.C. Da queimada "intergaláctica" ao cabo de "três forças”: uma experiência pedagógica sobre os usos dos jogos como conteúdo de ensino da educação física. Cadernos de Formação RBCE, p. 20-31, mar. 2016

OLIVEIRA, et al. (2014) Psicanálise e direitos humanos: o estatuto do ódio e o sujeito LGBT. Rev. Filos., Aurora, Curitiba, v. 26, n. 38, p. 131-153, jan./jun. 2014 